\title{
Treasury Single Account (TSA) and Revolving Funds in Public Institutions
}

\author{
Felix E. Ojong ${ }^{\mathrm{a}}$, A. M. Ogaboh Agba ${ }^{\mathrm{a}, *}$, Felix O. Eteng ${ }^{\mathrm{b}}$, Gbadebo S. Maruf ${ }^{\mathrm{c}}$, \\ Abayomi I. Akintola ${ }^{\mathrm{a}}$, \& E. U. Usung ${ }^{\mathrm{a}}$ \\ ${ }^{a}$ Department of Sociology, University of Calabar, Nigeria \\ ${ }^{b}$ Department of Public Administration, University of Calabar, Nigeria \\ ${ }^{c}$ School of Business Management, Universiti Utara Malaysia, Sintok, Kedah, Malaysia
}

\begin{abstract}
The study assessed the impact of Treasury Single Account (TSA) on revolving funds in public organisations, with particular reference to drug revolving fund in government hospitals in Nigeria. Specifically the study examines the relationship between appropriation control of TSA, cash management of TSA, payment mechanism of TSA and Drug Revolving Fund (DRF) in public hospitals. Survey method was adopted and 1020 questionnaire were administered. Data generated study were presented in tables and simple percentile. Hypotheses were also tested using Pearson Product Moment Correlation Coefficient (PPMC). Findings established significant links between appropriation control of TSA, cash management of TSA, payment mechanism of TSA and DRF in public hospitals. It was recommended among other that management should carryout monthly review of cash management of DRF to ensure that adequate funds are availability for drugs administration in public hospitals.
\end{abstract}

Keywords: Treasury single account, revolving fund, public institutions, corruption.

\section{Introduction}

Corruption remains a single major factor that obstructs development in Nigeria (Agba, Ikoh, Ushie \& Agba, 2008). Treasury single account (TSA) was introduced by President Buhari's administration as a measure to curb corruption, ensure accountability, transparency and efficiency in public organisations. TSA here refers to public account system which uses a single account or a set of linked account by ministries, departments or agencies of government to ensure that all revenue receipts and payments are done through a Consolidated Revenues Account (CRA) domiciled at Central Bank of Nigeria (Udo, 2016; Agba, Ocheni \& Nkpoyen, 2014; Ushie, Agba, Agba \& Chime, 2010). However, the introduction of TSA in government establishments especially in the health sector is not without consequence.

TSA is largely responsible for the increasing cases of lack of drugs in public hospitals under the Drug Revolving Fund (DRF) scheme. The administrative constrain associated with TSA impedes easy access to fund in public hospitals thus obstructing purchase and disbursement of drugs (Udo, \& Esara, 2016; Agba, Eteng, \& Coker, 2016). Although the TSA was structured to ensure availability and affordability of essential drugs to all and to ameliorate the burden of cost which has hindered individuals and households from accessing healthcare, the situation today is different from what is expected. In most public hospitals patients are advised to purchase required drugs from private pharmacies and dispensaries because of shortage of drugs. This has put many lives in danger, trauma and deaths. The low income worker have been the most affected as they are not able to purchase drugs. Consequently, many patients abandon treatment in public hospitals for traditional medicine, which has damaging effects due to lack of proper diagnosis and

\footnotetext{
* Corresponding author.

E-mail address: ogabohagbagroup@yahoo.com (A. M. Ogaboh Agba)
} 
dosage.

The continuous shortage of drug revolving fund (DRF) in public hospitals and the seeming inability of most public institutions to access recurrent funds to ease routine activities and duties calls for an empirical investigation to ascertain the effect of TSA on the operations of government establishments. The study assessed the impact of TSA on revolving funds in public organisations, with particular reference to drug revolving fund in government hospitals. Specifically, the study examines the relationship between appropriation control of TSA and DRF; it established the links between cash management of TSA and DRF; as well as assessed the correct between payment mechanism of TSA and DRF.

\section{Literature review and theoretical consideration}

\subsection{Conceptual elucidation and mismanagement of DRF}

The concept of DRF was introduced through the Bamako Initiative to be one of the ways of solving the challenges and difficulties in having availability of medicines in public hospital. DRF is a system whereby the revenue generated from the sale of drugs to patients is used to purchase new drugs and ensure availability, effective and efficient system. The aim is to provide safe and quality drugs at affordable price and is usually part of the wider user charge scheme (Uzochukwu, Onjekwe and Okpala, 2012). It is where the seed money provided by government, donor agencies or interested communities is used to purchase an original stock of essential and commonly used medicines to be dispensed at prices sufficient to replace the stock of medicines and ensures a continuous supply (Ogbona \& Nwako, 2016). DRF is very necessary in health care delivery in developing countries because essential medicines are critical to effective preventive and curative care.

The operational guidelines for the management of the DRF in the public hospitals includes the provision of adequate take off capital initially provided by the Federal Government, appropriate training of health professionals who are to serve as operators, setting up of a DRF Committee consisting of Doctors and Pharmacists, maintaining separate accounts with the Head of Department of Pharmacy as mandatory signatory, protecting the integrity of the DRF, and abiding by cost recovery policy guidelines (Ifijeh, 2018). The structure of DRF in public hospitals in Nigeria was designed to reflect the framework of the Bamako Initiative.

In most health institutions the scheme is experiencing challenges associated with non-accountability, depletion, and diversion of funds as well as undue political interference. The refusal of drug suppliers to continue to supply drugs to public hospitals due to unpaid debts proves that the funds are being mismanaged. The inability of the hospital management to adequately manage DRF has exposed patients to unnecessary hardship; some of which include: Patients are left with the option of purchasing drugs from private dispensers at exorbitant rate. Patients are exposed to fake and adulterated drugs. Patients are faced with difficulties accessing the prescribed drug in the open market. Delayed recovery due to patients' inability to use drugs at the appropriate time. Susceptibility to complication as a result of the inability to access the prescribed drug(s) on time.

\subsection{Treasure single account and DRF}

Successive administrations in Nigeria operated multiple accounts until the introduction of TSA. The scheme was introduced to regulate and ensure consolidations, accountability, transparency and optimal utilisation of government financial transactions. It also expected that economic prosperity will be achieved with the implementation of TSA (Okerekeoti \& Okoye, 2017). TSA was introduced to ensure institution effectiveness and efficiency. Unfortunately, since the implementation of TSA by the Buhari's administration, many federal establishments are yet to experience optimal performance while some are worst-off. According to Adetula Adegbenjo, Owolabi. Achugamonu, and Ojeka (ud), TSA drives liquidity squeeze and escalate interest rate in commercial banks. It accounts for job lost and significantly obstruct borrowing in banks. It reduces government deposits and shrinks liquidity in commercial banks. The negative implication of TSA is not only limited to the banking sector as it shrinks revolving funds meant for recurrent expenditure and obstruct urgent maintenance activities of Ministries, Departments and Agencies (MDAs). Many institutions cannot urgently meet the demands of clients. In federal tertiary hospitals generators are not easily 
fuelled and drugs replacements is a serious challenge. DRF are not readily available to pay suppliers.

\subsection{Theoretical consideration}

Structural functionalism is a modified version of the classical functional theory of Emile Durkheim. In his effort to restructure the functional theory to explain the change in human society, which functional theory lack, Talcott Parsons (1902-1979) developed structural functionalism as a theoretical perspective that seeks to explain the role that each subset of the social system plays in making sure that the entire system function and progresses. Parsons acknowledges that to every system, there exists subsystems that cannot function independently but requiring cooperation from other subsystems. The main premise of structural functionalism is that while each subsystem contributes to the survival of other subsystems, their survival in turn contributes to its survival as well. Just like the classical functional theory, the failure of a part to function optimally, ultimately lead to the breakdown of the entire system.

Looking at the effect of TSA on DRF in public hospitals; subcomponents of TSA which include appropriation control, cash management and payment mechanism were identified. These subcomponents contribute interdependently and interrelatedly for the benefit of the entire hospital system. In this regards TSA determines whether the account unit will function effectively or not. The role of the account unit influenced other units in the hospital. DRF is also dependent on the account unit as regulated by TSA. Similarly, TSA also influence availability of funds as well as the functioning of pharmaceutical departments in public hospitals. If these two units fail in their functions as a result of TSA, the entire system (that is the hospital) will collapse. TSA also serves as part of the external environment which influences the organism (system) called the hospital.

This suggests that no system is totally static, the hospital system experiences friction and changes which are imported from the external environment, in this instance, government policy (TSA). However, this chances introduce by TSA has not led to the collapse of the entire system (hospital). This explains the fact that no amount of cohesion, interdependence and interrelatedness can prevent frictions in the system. Notwithstanding its criticism, structural functionalism has been a dependable theoretical framework in the explanation of the survival and functionality of social systems.

\section{Methods}

Survey method that allows for the use of questionnaire was adopted. The design allows researchers to sample the opinion of a subunit of a population inorder to derive information on a topic under discussion (Angioha, Nwagboso, Ironbar, \& Ishie, 2018; Angioha, Agba, Kenneth, \& Ishie, 2021; Angioha, Enukoha, Agba, \& Ikhizamah, 2020; Ukwayi, Akintola \& Angioha, 2019). Information for the study was gathered from medical officials in tertiary hospitals in Calabar Metropolis, Cross River State, Nigeria. Specifically, the study sampled opinion from staff and patients in the departments of pharmacy and 15 wards of inpatient units. These units and patients were carefully selected to provide information on the availability and accessibility of drugs in public hospitals.

The instrument of data collection for this study was questionnaire. A total of 1100 questionnaire were administered on selected respondents. The instrument was structured in two sections. The first part sought demographic data of respondents, while second part sought opinions on the effect of TSA on DRF in public hospital. The questions were structured in three blocks, each seeking to obtain information relating to appropriation control, cash management, payment mechanism and DRF. The data generated for this study were presented in tables and simple percentile. Hypotheses were also tested using Pearson Product Moment Correlation Coefficient (PPMC) to establish the links between TSA and DRF.

\section{Result and Discussions}

\subsection{Data presentation}

Table 1 shows the demographic data of respondents in wards and departments selected for the study. The table shows that 436 respondents, representing 42.74 percent were males while 584 respondents, representing 57.25 percent were 
females. Age distribution of respondents shows that 15 to 24 years were 80 (7.84\%), 25 to 34 years were $94(9.21 \%)$, between 35 to 44 years were $127(12.45 \%)$, ages of 45 to 54 years were 323 (31.67\%), 55 to 64 years were 216 $(21.17 \%)$ while 180 respondents $(17.64 \%)$ were identified to be between 65 years and above.

Table 1. Demographic data of participants

\begin{tabular}{clcc}
\hline Bio-data of respondent & Designation & Outcome & Percentage (\%) \\
\hline 1. Sex & Male & 436 & 42.74 \\
& Female & 584 & 57.25 \\
2. Age & $15-24$ & & 7.84 \\
& $25-34$ & 94 & 9.21 \\
& $35-44$ & 127 & 12.45 \\
& $45-54$ & 323 & 31.67 \\
& $55-64$ & 216 & 21.17 \\
& 65 \& Above & 180 & 17.64 \\
3. Ward & & & \\
& Pediatric surgical & 28 & 2.74 \\
& Pediatric medical & 53 & 5.19 \\
& Male surgical & 71 & 6.96 \\
& Male medical & 106 & 10.39 \\
& Female surgical & 123 & 12.05 \\
& Female medical & 117 & 11.47 \\
& Casualty & 44 & 4.31 \\
& Labor & 66 & 6.47 \\
& Post natal & 214 & 20.98 \\
& Antenatal & 198 & 19.41 \\
& & & 37.35 \\
& Hospital duration of & 381 & 20.49 \\
patients & 0-1 week & 209 & 36.96 \\
& $1-2$ weeks & 377 & 5.19 \\
\hline
\end{tabular}

In selecting respondents according to wards, using accidental and volunteer sampling technique, Table 1 shows that 28 respondents $(2.74 \%)$ were selected from the paediatric surgical ward; 53 respondents $(5.19 \%)$ from the paediatric medical ward, 71 respondents $(6.96 \%)$ from the male's surgical ward while 106 respondents $(10.39 \%)$ were from the male medical ward. It further shows that 123 respondents $(12.05 \%)$ were from the female surgical ward; 117 respondents $(11.47 \%)$ from the female medical ward; 44 respondents $(4.31 \%)$ from the casualty ward while 66 respondents $(6.47 \%)$ were from the labour ward. The post-natal and antenatal wards had 214 and 198 respondents, representing 20.98 percent and 19.41 percent, respectively. Table 1 also shows that 381 patients $(37.35 \%)$ had spent less than a week in the hospital; 209 respondents (20.49\%) have been in on admission for 2 weeks while 377 respondents $(36.96 \%)$ have been in the wards for up to a month. However, only 53 respondents (5.19\%) who participated in the study reported that they have been on admission for more than one month.

Table 2. Responses measuring from patients' showing availability and accessibility to drugs

\begin{tabular}{lllll}
\hline S/N & Questions & Observations & Frequency & Percentage (\%) \\
\hline 5 & Do you get all the drugs you need & Agreed & 122 & 11.96 \\
& from the hospital? & Disagreed & 891 & 87.35 \\
& & No response & 7 & 0.68 \\
6 & Does it take longer time to get the & Agreed & 379 & 37.15 \\
& drugs you need in the hospital? & Disagreed & 641 & 62.84 \\
& & No response & 0 & 0 \\
\hline
\end{tabular}




\begin{tabular}{lllll}
\hline S/N & Questions & Observations & Frequency & Percentage (\%) \\
\hline 7 & Do you usually get your drugs from & Agreed & 896 & 87.84 \\
& outside the hospital? & Disagreed & 123 & 12.05 \\
& & 1 & 0.09 \\
8 & Drugs in the hospital are more & & 17.15 \\
& expensive than the ones bought & & 833 & 81.67 \\
& outside? & 12 & 1.17 \\
\hline
\end{tabular}

Table 2 assessed the availability and accessibility of drugs by patients. It shows that 122 respondents (11.96\%) opined that they get all their drugs from the hospital while 891 respondents $(87.35 \%)$ reported that they do not always get all the drugs needed from the hospital; 7 respondents $(0.68 \%)$ did not respond to this question. To examine the duration it takes for patients to access drugs in the hospital, 379 respondents $(37.15 \%)$ indicated that it takes them longer time to access drugs while 641 respondents $(62.84 \%)$ disagreed. Responds to whether patients purchased drugs outside the hospital shows that 896 respondents $(87.84 \%)$ agreed that they purchased drugs outside while 123 respondents $(12.05 \%)$ disagreed. Only 1 respondent $(0.09 \%)$ did not respond to this question. To assess whether drugs in public hospitals were more expensive than those purchased outside shows that 175 respondents $(17.15 \%)$ agreed while 833 respondents $(81.67 \%)$ disagreed; suggesting that drugs purchased from the hospital were cheaper than those in private pharmaceutical shops. Only 12 respondents $(1.17 \%)$ did not respond to this question.

Table 3. Responses assessing appropriation control and DRF

\begin{tabular}{lllll}
\hline S/N & Questions & Observations & Frequency & Percentage (\%) \\
\hline 9 & Did the current budget adequately & Agreed & 29 & 36.25 \\
& capture the needs of the DRF in your & Disagreed & 46 & 57.5 \\
& hospital? & No response & 5 & 6.25 \\
10 & Has the budget implementation & Agreed & 31 & 38.75 \\
& improved the performance of DRF & Disagreed & 42 & 52.5 \\
& in your hospital? & No response & 7 & 8.75 \\
11 & Are there budgetary provisions for & Agreed & 46 & 57.5 \\
& the DRF that are not being & Disagreed & 23 & 28.75 \\
12 & implemented? & No response & 11 & 13.75 \\
& Is there a dwindling/shortage in the & Agreed & 75 & 93.75 \\
& supply of drugs because of DRF? & Disagreed & 4 & 5 \\
\end{tabular}

Table 3 shows the responses of staff from the pharmaceutical unit assessing appropriation control and DRF. To examine whether the budget for the funding of DRF captured all the needs of the unit, 29 respondents $(36.25 \%)$ agreed, while 46 respondents $(57.5 \%)$ disagreed. Only 5 respondents $(6.25 \%)$ did not respond to this question. To assess whether the implementation of the budget has improved the performances of the DRF in the hospital; 31 respondents (38.75\%) agreed that it improves DRF in the hospital, while 42 respondents $(52.5 \%)$ disagreed. Only 7 respondents $(8.75 \%)$ did not respond to this question. To investigate whether there are budgetary provisions that are not being implemented in the hospital, 46 respondents (57.5) agreed while 23 respondents (28.75\%) disagreed. Only 11 respondents $(13.75 \%)$ did not respond to this question. Responding to the question whether there is a dwindling supply of drugs in the administration of DRF; 75 respondents (93.75\%) reported a dwindling supply of drugs, while 4 respondents $(5.0 \%)$ disagreed. Only 1 respondent, representing 1.25 percent did not respond to this question.

Table 4. Responses assessing cash management and DRF

\begin{tabular}{lllcc}
\hline S/N & Questions & Observations & Frequency & Percentage (\%) \\
\hline 13 & Monies from sales of drugs are kept & Agreed & 65 & 81.25 \\
& with the store unit? & Disagreed & 14 & 17.5 \\
& & No response & 1 & 1.25 \\
14 & Profit from sales of drugs is & Agreed & 21 & 26.25 \\
& constantly used in purchasing more & Disagreed & 57 & 71.25 \\
& drugs? & No response & 2 & 2.50 \\
\hline
\end{tabular}




\begin{tabular}{lllcc}
\hline S/N & Questions & Observations & Frequency & Percentage (\%) \\
\hline 15 & Money approved for DRF does not & Agreed & 24 & 30 \\
& get to the hospital & Disagreed & 39 & 48.75 \\
\multirow{4}{*}{16} & & No response & 17 & 21.25 \\
& Funds released for DRF are & Agreed & 58 & 72.50 \\
& sometimes used for other purposes & Disagreed & 9 & 11.25 \\
& & No response & 13 & 16.25 \\
\hline
\end{tabular}

Table 4 shows the responses of staff of pharmacy department on cash management and DRF. Investigating whether the money generated from the sales of drug was kept in the store as prescribed by the guidelines establishing DRF; 65 respondents $(81.25 \%)$ reported that the money was kept in the vault while 14 respondents $(17.5 \%)$ disagreed. Only 1 respondent $(1.25 \%)$ did not respond to this question. To assess whether monies from sales of drugs from the DRF were frequently used for the re-purchase of new drugs; 21 respondents $(26.25 \%)$ agreed while 57 respondents $(71.25 \%)$ reported that the money accrued from the sales of drugs was not immediately used for the purchase of new drugs; only 2 respondents $(2.50 \%)$ did not respond to this question. Responses on whether funds budgeted for the purchase of drugs in the hospital were accessible, 24 respondents $(30.0 \%)$ agreed that the money was accessible while 39 respondents $(48.75 \%)$ disagreed. While, 17 respondents $(21.25 \%)$ did not respond to this question. Investigation on whether funds appropriated for DRF are usually diverted, 58 respondents $(72.50 \%)$ agreed while 9 respondents $(11.25 \%)$ disagreed; while 13 respondents $(16.25 \%)$ did not respond to this question.

Table 5. Responses measuring payment mechanism and DRF

\begin{tabular}{|c|c|c|c|c|}
\hline $\mathrm{S} / \mathrm{N}$ & Questions & Observations & Frequency & Percentage $(\%)$ \\
\hline \multirow[t]{3}{*}{17} & \multirow{3}{*}{ Drug suppliers are promptly paid } & Agreed & 5 & 6.25 \\
\hline & & Disagreed & 74 & 92.5 \\
\hline & & No Response & 1 & 1.25 \\
\hline \multirow[t]{3}{*}{18} & \multirow{3}{*}{$\begin{array}{l}\text { Drug suppliers do not promptly } \\
\text { supply drugs due to delay in } \\
\text { payment }\end{array}$} & Agreed & 77 & 96.25 \\
\hline & & Disagreed & 3 & 3.75 \\
\hline & & No Response & 0 & 0 \\
\hline \multirow[t]{3}{*}{19} & \multirow{3}{*}{$\begin{array}{l}\text { Lack of essential drugs in the store } \\
\text { has affect administration of DRF }\end{array}$} & Agreed & 68 & 85 \\
\hline & & Disagreed & 9 & 11.25 \\
\hline & & No Response & 3 & 3.75 \\
\hline \multirow[t]{3}{*}{20} & \multirow{3}{*}{$\begin{array}{l}\text { Hospital management order drugs on } \\
\text { credit, pending when funds are } \\
\text { released. }\end{array}$} & Agreed & 61 & 76.25 \\
\hline & & Disagreed & 15 & 18.75 \\
\hline & & No Response & 4 & 5 \\
\hline
\end{tabular}

Table 5 measures the relationship between payment mechanism and drug revolving fund. To investigate whether drug suppliers were promptly paid, 5 respondents $(6.25 \%)$ agreed that the drug suppliers were promptly paid while 47 respondents $(92.5 \%)$ disagreed. Only 1 respondent $(1.25 \%)$ did not respond to this question. To ascertain whether lack of prompt payment was affecting supplies, 77 respondents $(96.25 \%)$ agreed that suppliers usually delay supplies due to delayed payments. Only 3 respondents $(3.75 \%)$ did not respond to this question. In responding to question whether lack of essential drugs in store affect effective treatment in the hospital, 68 respondents (85.0\%) agreed that lack of drugs affect efficient treatment of patients while 9 respondents $(11.25 \%)$ disagreed. While 3 respondents $(3.75 \%)$ did not respond to the question. To investigate whether the management of DRF usually order drugs on credit, pending when funds are released, 61 respondents $(76.25 \%)$ agreed that drug suppliers usually supply drugs on credit; 15 respondents $(18.75 \%)$ disagreed; while 4 respondents $(5.0 \%)$ disagreed.

\subsection{Test of hypotheses}

\subsubsection{Hypothesis one}

There is no significant relationship between appropriation control of TSA and DRF. This hypothesis was tested using responses from questions 5, 6, 7 and 8 plotted in Table 2 and questions 9, 10, 11 and 12 plotted in Table 3. These tables measured appropriation control and drug accessibility. 
Table 6. Pearson product moment correlation analysis of the relationship between appropriation control of TSA and DRF $(\mathrm{N}=1100)$

\begin{tabular}{lllll}
\hline Variables & $\sum \mathrm{x}$ & $\sum \mathrm{x}^{2}$ & $\sum \mathrm{XY}$ & $\mathrm{I}$ \\
\hline DRF (x) & $\sum \mathrm{y}$ & $\sum \mathrm{y}^{2}$ & & \\
& 4060 & 845296 & 40230 & 0.79 \\
Appropriation control of TSA (y) & 296 & 3016 & & \\
\hline Significance: $0.05 ;$ f - - ; Critical Value $-0.707 ; N=1100$ & &
\end{tabular}

At 6 degrees of freedom and 0.05 level of significance, the critical value of this hypothesis was 0.707 . The analysis of this hypothesis accepted the null hypothesis and rejected the alternate hypothesis. This is because the $t$-cal value of 0.79 is less than 1. The outcome of this test showed that there was a perfect negative correlation between appropriation control and DRF. The outcome of this study shows that appropriation control of TSA has no implication on the administration of DRF in public hospitals in Nigeria.

\subsubsection{Hypothesis two}

Cash management of TSA does not significantly relate to DRF. This hypothesis was tested using responses from questions 5, 6, 7 and 8 plotted in Table 2 and questions 13, 14, 15 and 14 plotted in Table 4. These Tables measured, cash management and accessibility of drugs.

Table 7. Pearson product moment correlation analysis of the relationship between cash management of TSA and DRF $(\mathrm{N}=1100)$

\begin{tabular}{|c|c|c|c|c|}
\hline Variables & $\begin{array}{l}\sum \mathrm{x} \\
\sum \mathrm{y}\end{array}$ & $\begin{array}{l}\sum x^{2} \\
\sum y^{2}\end{array}$ & $\sum X Y$ & І \\
\hline $\operatorname{DRF}(\mathrm{x})$ & 4060 & 48049 & \multirow[b]{2}{*}{48145} & \multirow[b]{2}{*}{1} \\
\hline Cash management of TSA (y) & 364 & 48045 & & \\
\hline
\end{tabular}

At 6 degrees of freedom and 0.05 level of significance, the critical value of this hypothesis was 0.707 while the sample size was 1100 respondents. From the result of the analysis, the null hypothesis was rejected while the alternate hypothesis was accepted. This was because the $t$-cal value of 1 was greater than 0 . Therefore, the outcome of this analysis shows that there was a perfect positive correlation between cash management of TSA and DRF in public hospitals in Nigeria. This finding shows that cash management has significant implication on the administration of DRF.

\subsubsection{Hypothesis three}

There is no significant relationship between payment mechanism and DRF. This hypothesis was tested using responses from questions 5, 6, 7 and 8 plotted in Table 2 and responses from questions 17, 18, 19 and 20 plotted in Table 5. These tables measured payment mechanism and drug accessibility in public hospitals.

Table 8. Pearson product moment correlation analysis of the relationship between payment mechanism and DRF $(\mathrm{N}=1100)$

\begin{tabular}{|c|c|c|c|c|}
\hline Variables & $\begin{array}{l}\sum \mathrm{x} \\
\sum \mathrm{y}\end{array}$ & $\begin{array}{l}\sum \mathrm{x}^{2} \\
\sum \mathrm{y}^{2}\end{array}$ & $\sum X Y$ & 厂 \\
\hline $\operatorname{DRF}(\mathrm{x})$ & 712 & 3226 & \multirow[b]{2}{*}{3269} & \multirow[b]{2}{*}{1} \\
\hline Payment mechanism of TSA (y) & 364 & 3315 & & \\
\hline
\end{tabular}

Significance: 0.05 (One-tailed); $D f-2 ; r$-tab val $=0.950 ; N=1100$

At 2 degrees of freedom and 0.05 level of significance, the table value of this hypothesis was 0707. From the analysis, the alternate hypothesis was accepted while the null hypothesis was rejected. This was because the $t$-cal value of 1 was greater than 0 . The outcome of this test shows that there is a perfect positive correlation between payment mechanism and administration of DRF in public hospitals in Nigeria. This finding shows that the payment mechanism of TSA has significant effect on DRF. 


\subsection{Discussion of findings}

The finding of this study is revealing. It shows that appropriation control does not have significant implication on the management of DRF in public hospitals. It shows a perfect negative correlation between appropriation control of TSA and DRF. The result of this hypothesis agrees with Murakami, Phommasack, Oula and Sinxomphou (2001) who noted that appropriation of funds for the procurement of drugs does not have significant implication on the administration of the DRF. According to Murakami, et al. (2001), once the initial coital is set up and efficiently managed, subsequent appropriation for the operation of the hospital does not directly influence the management of DRF. This finding also aligned with the views of Ali (2009) who opines that the initial start-up capital for the administration of the DRF is enough to sustain its administration without relying on appropriations.

Again, the outcome of this study shows that cash management of TSA has significant implication on the management of DRF in Nigeria. It reveals that there is a perfect negative correlation between cash management and administration of DRF. This finding tallies with Ogbona and Nwako (2016) who identified cash management as the engine that ensures efficiency in the management of DRF. They stressed that if cash provided for the take-off of DRF is not properly managed, drug administration will be negatively affected. This finding also agrees with Nunan and Duke (2011) and Yuqing, Chaojie, Liu and Xinping (2017) that cash management is an essential component for effectiveness administration of DRF. Lack of transparency in the management of cash as a result of the TSA regime constitutes a significant constraint to the administration of DRF in hospitals across Nigeria.

The study shows that payment mechanism has significant implication on the management of DRF in public hospitals. It reveals a perfect positive correlation between payment mechanism and drug revolving fund. This result confirms the views of Uzochukwu, Ughasoro, Etiaba, Okwuosa, Envuladu and Onwujekwe (2015), who noted that payment mechanism contributes significantly to the sustenance and success of DRF as well as its failure. They noted that with population growth and the concomitant effect of increased demand for healthcare services, the need for adequate budgeting and transparent payment system is needed to ensure a successful management of DRF. This finding also agrees with Abegunde and Asuzu (2013) who found that inconsistent payment mechanism was the prevalent factor for lack of essential drugs in hospitals operating DRF.

\section{Conclusion and recommendations}

This study on the implications of the TSA on DRF was carried out in public hospitals in Nigeria. Three variables were identified for the study, which include appropriation control, cash management and payment mechanism as practiced under TSA system. These variables formed the study's specific objectives and hypotheses. The workability of the DRF was given a theoretical explanation using structural functionalism. A sample size of 1100 respondents was selected using accidental and volunteer sampling techniques. The instrument of data collection was questionnaire. After testing the hypotheses, the study found that there was no significant implication between appropriation control and the efficiency of DRF. The study also revealed that there is a significant implication between cash management and the administration of DRF. Lastly, the study found that there is signification relationship between payment mechanism and DRF. Based on these findings, the following recommendations were made:

(1) The Board managing DRF operations in public hospitals should be encouraged to review the budget of the scheme prior the commencement of every fiscal year in order to address the issue of appropriation uncertainties as well as improved its operational efficiency.

There should be proper monitory and evaluation of cash management of DRF in public hospitals to ensure that there is adequate compliance to the directives regarding deposits, withdrawals and payment to suppliers. The contract for the supply of drugs to public hospitals under the DRF scheme should be awarded to specific contractors with quarterly review of the payment module 


\section{References}

Abegunde, K. \& Asuzu, M. (2013). Facility user's preference between the free and the Bamako Initiative (Drug Revolving Fund-Based) Health Services in Iwajowa Local Government, Oyo State. Journal of Community Medicine and Primary Health Care, 26(2), 1-6.

Adetula, D., Adegbenjo, S., Owolabi. F., Achugamonu, U. \& Ojeka, S. (ud). Treasury single account policy and government revenue in Nigeria. Journal of Internet Banking and Commerce. Available online at: http://www.icommerce.central.com/ArchiveJIBC... Retrieved 1/7/19

Agba, A. M. O., Eteng, F. O., \& Coker, F. G. (2016). Skills training and workers' productivity in Cross River State, Nigeria. FULafia Journal of Social Sciences (Maiden Edition), 327-341.

Agba, A. M. O., Ikoh, M. U., Ushie, E. M. \& Agba, M. S. (2008). Bureaucratic corruption in Nigeria: The need for institutional reforms. Journal of International Politics and Development Studies, 4(2), 187-204.

Agba, A. M. O., Ocheni, S. \& Nkpoyen, F. (2014). Microfinance credit scheme and poverty reduction among lowincome workers in Nigeria. Journal of Good Governance and Sustainable Development in Africa, 2(1).

Agba, M.S., Agba, A.M.O., Ushie, E.M., \& Akwara, A.F. (2009) "Poverty, Food Insecurity andthe Rebranding Question in Nigeria." Canadian Social Sciences 5 (6) pp1-9.

Ali, G. F. (2009). How to establish a successful revolving drug fund: the experience of Khartoum in Sudan. Bulletin of World Health Organization, 87(2), 139-142.

Angioha, P. U., Agba, R. U., Kenneth, B. U., \& Ishie, E. U. (2021). Improving The Effectiveness of Commercial Bank Employess in Cross River State Through Appropriate Remuneration. Quantitative Economics and Management Studies, 2(3), 158-162. https://doi.org/10.35877/454ri.qems275

Angioha, P. U., Enukoha, C. U., Agba, R. U., \& G. U, I. (2020). Information technology predictor variables and employee productivity in commercial banks. JINAV: Journal of Information and Visualization, 1(1), 44-52. https://doi.org/10.35877/454RI.jinav2125

Angioha, P. U., Nwagboso, S. N., Ironbar, A. E. \& Ishie, E. U. (2018). Underemployment: A sociological and policy analysis of workers well-being in hospitality industry in Calabar, Cross River State, Nigeria. IOSR Journal of Humanities and Social Science (IOSR-JHSS), 23(6), 57-66.

Ibiam, A. A., Bekomson, E. M., \& Angioha, P. U. (2019). socio-environmental factors as determinants of social wellbeing of adolescents in calabar, cross river state, nigeria. European Journal of Public Health Studies, l(2), 164-175. https://doi.org/10.5281/zenodo.3597522

Ifijeh, M. (2018). Lack of viable drugs revolving fund threatens national security. ThisDay Online: August 30, 2018.

Murakami, H., Phommasack, B., Oula, R. \& Sinxomphou, S. (2001). Revolving drug funds at front-line health facilities in Vientiane, Lao PDR. Journal of Health Policy and Planning. 16(1), 98-106.

Nunan, M. \& Duke, T. (2011). Effectiveness of pharmacy interventions in improving availability of essential medicines at the primary healthcare level. European Journal of Tropical Medicine and International Health, 16(5), 647-658.

Ogbona, B. \& Nwako, C. (2016). Essential drugs revolving fund scheme in Nigeria: From the edge of a precipice towards sustainability. Journal of Advanced Medicine and Pharmaceutical Sciences, 8(2), 1-8.

Okerekeoti, C. U. \& Okoye, E. I. (2017). Treasury single account (TSA) in Nigeria: A theoretical perspective. The 2017 International Conference on African Entrepreneurship and Innovation for Sustainable Development (AEISD). Online available at researchgate.net/.../-Treasury-single-account-TSA-IN-Nig. Retrieved 1/7/19.

Udo, E. J. \& Esara, I. E. (2016). Adoption of treasury single accoungt (TSA) by state government of Nigeria: Benefits, challenges and prospects. Journal of Finance and Accounting, 4(3), 126-130. 
Ukwayi, J. K., Akintola, A., \& Angioha, P. U. (2019). Biometric security in business organisation: An assessment of its' impact on checking corporate crime in business organizations in cross river state nigeria. International Journal of Scientific and Research Publications (IJSRP), 9(5), p8966. https://doi.org/10.29322/ijsrp.9.05.2019.p8966

Ushie, E. M., Agba, A. O, Agba, M. S. Chime, J. (2010). leadership style on employees' intrinsic job satisfaction in the Cross River State Newspaper Corporation, Calabar, Nigeria. International Journal of Development and Management Review 5 (1), 61-74

Uzochukwu, B., Onjekwe, O. \& Okpala, C. (2012). Effect of the Bamako initiative drug revolving fund on the availability and rational use of essential drug in primary health care facilities in south-east Nigeria. Journal of Health Policy and Planning, 17(4), 378-383

Uzochukwu, B., Ughasoro, M., Etiaba, E., Okwuosa, C., Envuladu, E. \& Onwujekwe, O. (2015). Healthcare financing in Nigeria: Implications for achieving universal health coverage. Nigerian Journal of Clinical Practice. 18(4), 337-444.

Yuqing, T., Chaojie, Liu, \& Xinping, Z. (2017). Delivery of essential medicines to primary care institutions and its association with procurement volume and price: A case study in Hubei Province, China. Applied Health Economics and Health Policy, 15(1), 57. 